\title{
Microstructural Analysis of Al-Al4C3 Nanocomposites Produced in Solid State
}

\author{
A. Santos-Beltrán , R. Martínez-Sánchez ${ }^{* *}$, E. García-Sánchez*, P. de Lira-Gómez*, W. Antúnez- \\ Flores $^{* *}$ and V. Gallegos-Orozco* \\ *Unidad académica de Ingeniería I. Universidad Autónoma de Zacatecas, Av. López Velarde 801, \\ C. P. 98000. Zacatecas, Zac. México. \\ *** Centro de Investigación en Materiales Avanzados (CIMAV), Miguel de Cervantes No. 120, C.P. \\ 31109, Chihuahua, Chih., México
}

A wide range of production techniques have been developed for aluminum matrix composites materials. This is generally done by dispersion of high temperature resistant fine ceramic reinforcement particles in the aluminum structure. Even though a number of processing techniques are available for producing Metal Matrix Composites (MMCs), the Mechanical Milling (MM) using Powder Metallurgy (PM), is a useful technique to synthesize composites of aluminum matrix. The conventional PM route for making Al matrix composites include: (1) Al is blended or mechanically alloyed with reinforcement particles; (2) compaction by die pressing, and (3) sintering [1]. The reinforcing particles $\mathrm{Al}_{4} \mathrm{C}_{3}$ have become an interesting reinforcing material because their high level of physical and mechanical properties, e.g. high temperature strength, thermal cyclic resistance, wear resistance and low linear expansion coefficient [2]. Therefore, the reinforcement of the aluminum using $\mathrm{Al}_{4} \mathrm{C}_{3}$ has recently become the subject of many studies and widely used for products and structures [3].

$\mathrm{Al}_{4} \mathrm{C}_{3}$ was synthesized by mixing 0.75 wt. $\%$ of $\mathrm{Al}$ powder and 0.25 wt. $\%$ of $\mathrm{C}$ powder, the mixture was mechanically milled in a high energy Simoloyer mill during $8 \mathrm{~h}$. Argon was used as atmosphere milling. The device and milling media used were made from hardened steel.

Consolidated samples were heat treated for $2 \mathrm{~h}$ at $650^{\circ} \mathrm{C}$. According with the $\mathrm{X}$ ray analyses, the product obtained is a mixture of $\mathrm{Al}-\mathrm{C}-\mathrm{Al}_{4} \mathrm{C}_{3}$ where the $\mathrm{Al}$ and $\mathrm{C}$ are remaining elements indicating that not all the mixture Al-C powder was transformed into to Al4C3. The Al-C-A14C3 mixture was called $\mathrm{M}$.

Al-based composites were produced by mixing Al powder (99.5\% purity) and various powder mixtures composed by Al-1, 2 and 3 wt. \% of M. Each Al-M mixtures powders were mechanically milled in a high energy Simoloyer mill during $8 \mathrm{~h}$. Argon was used as the milling atmosphere. Consolidated samples were sintered at different times: $2 \mathrm{~h}, 4 \mathrm{~h}$ and $6 \mathrm{~h}$ at $550^{\circ} \mathrm{C}$.

The Fig. 1 shows the X-ray diffraction patterns of Al-3 wt. \% M in the as-milled condition and sintered at 2, 4 and $6 \mathrm{~h}$. These results suggest the remaining $\mathrm{C}$ from the $\mathrm{M}$ powder reacts with the aluminum during the sintering process and the quantity of Al4C3 increase over the minimum detection limit of the X-ray technique used. The AFM topography analysis carried out on Al-2wt. \% $\mathrm{M}$ at $6 \mathrm{~h}$ of sintering sample (see Fig. 2) show a nanostructured state even after 6 hour of heat treatment. The profile graph shows the heights of the crystallites. Also the SEM secondary electron image of Fig. 3 for the Al-1 wt. \% M sample at $2 \mathrm{~h}$ of sintering shows the existence of small crystallites in sintered zones after $4 \mathrm{~h}$ of sintering.

The TEM bright-field image (see Figure 4) shows an $\mathrm{A}_{4} \mathrm{C}_{3}$ nanoparticle into the $\mathrm{Al}$ matrix and the presence of small crystallites in the Al-2wt. \% M sample after $2 \mathrm{~h}$ of sintering. Some $\mathrm{A}_{4} \mathrm{C}_{3}$ 
nanoparticle grows up on the crystallite as is appreciable in the TEM image. At seem the presence of the $\mathrm{A}_{4} \mathrm{C}_{3}$ nanoparticle into the $\mathrm{Al}$ matrix avoid the crystallite grow during the sintering process,

\section{References}

[1] Halil Arik, Materials and Design 29 (2008) 1856-1861

[2] G. Abouelmagd. Journal of Materials Processing Technology (2004).

[3] A. Santos et al. Journal of Alloys and Compounds (2010).

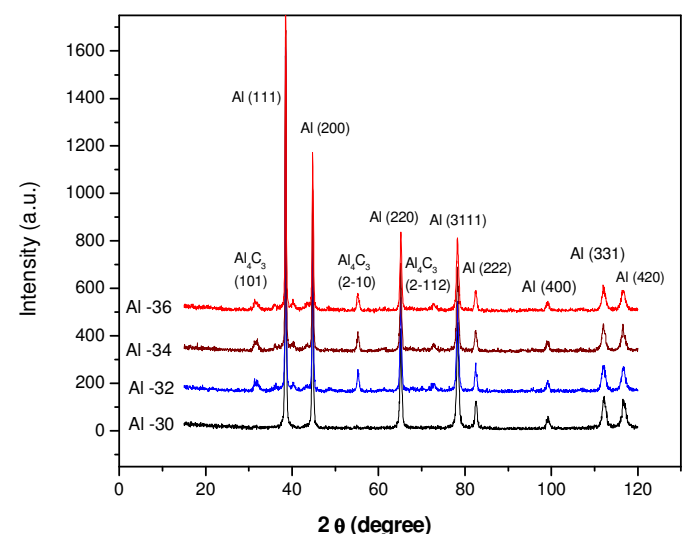

Figure 1. X-ray diffraction patterns of the Al-3 wt. \% $\mathrm{M}$ at 2, 4 and $6 \mathrm{~h}$ of sintering samples.

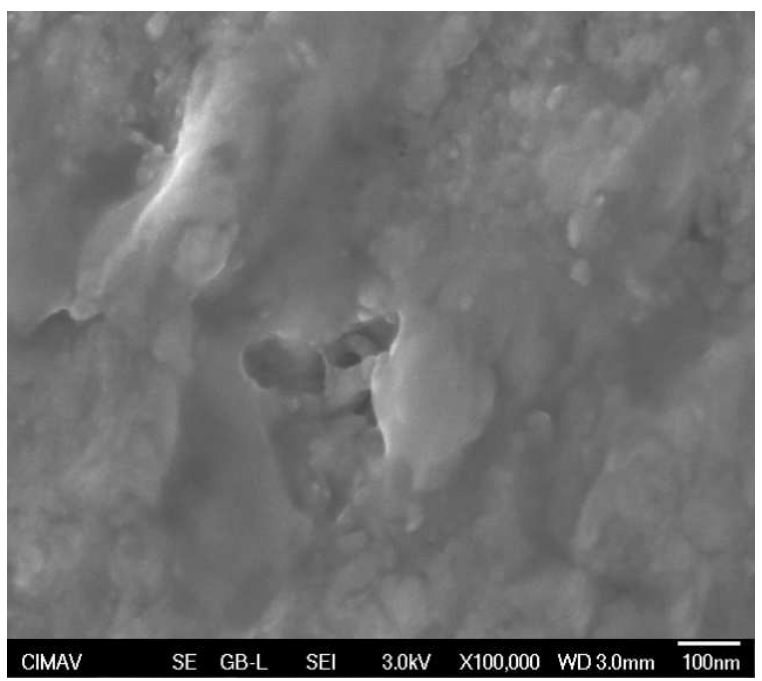

Figure 3. SEM secondary electron image for the Al-1 wt. \% $\mathrm{M}$ sample at $2 \mathrm{~h}$ of sintering.
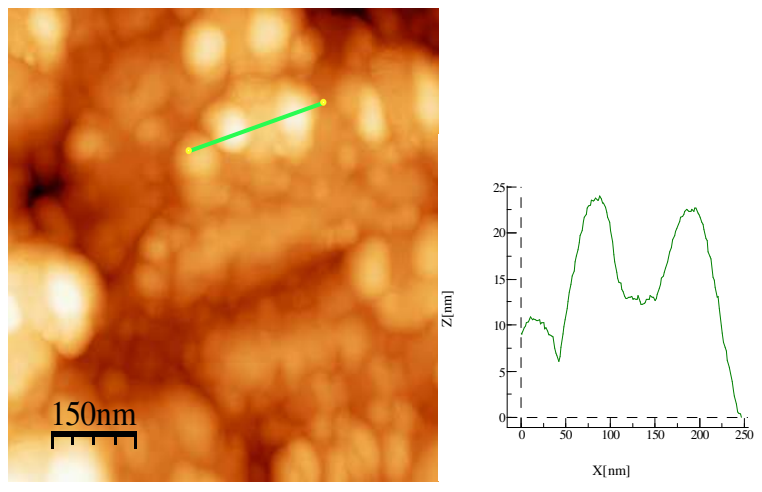

Figure 2. Atomic Force Microscopy topography image and profile graph of the Al-2 wt. \% M at $6 \mathrm{~h}$ of sintering sample.

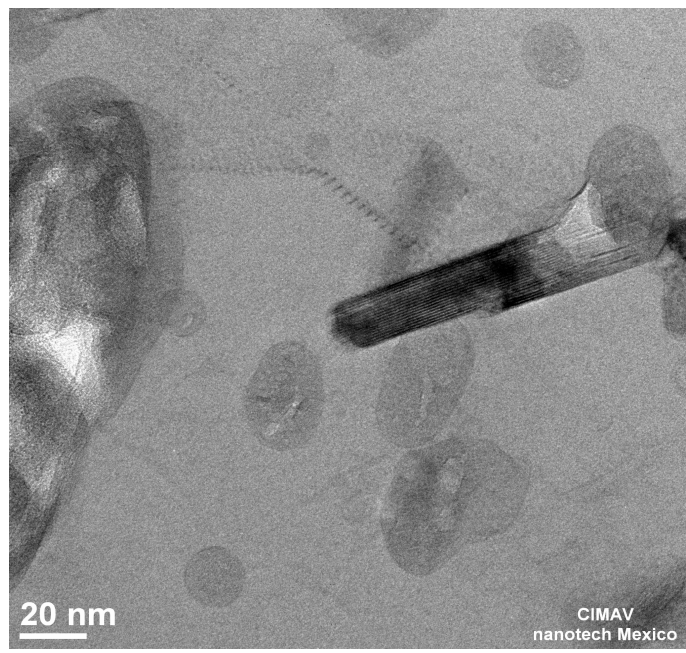

Figure 4. TEM bright-field that shows an aluminum carbide nanoparticle and some crystallites present in the Al matrix of the Al- 2 wt. $\% \mathrm{M}$ sample at $2 \mathrm{~h}$ of sintering. 